\title{
La UNIA inaugura un espacio de debate permanente sobre patrimonio cultural
}

El pasado mes de enero se presentaba el "Seminario permanente de patrimonio histórico de la UNIA", iniciativa para debatir y reflexionar sobre el patrimonio cultural desde los presupuestos teóricos y metodológicos que distinguen esta universidad y que le otorgan una personalidad propia con una oferta formativa diferente, caracterizada por propiciar espacios de debate, investigación e intercambio de experiencias abiertos y flexibles. La sede Antonio Machado, en Baeza, será el eje y ubicación para el desarrollo de las actividades y la programación de este seminario, que permanecerá abierto a lo largo de los próximos años.

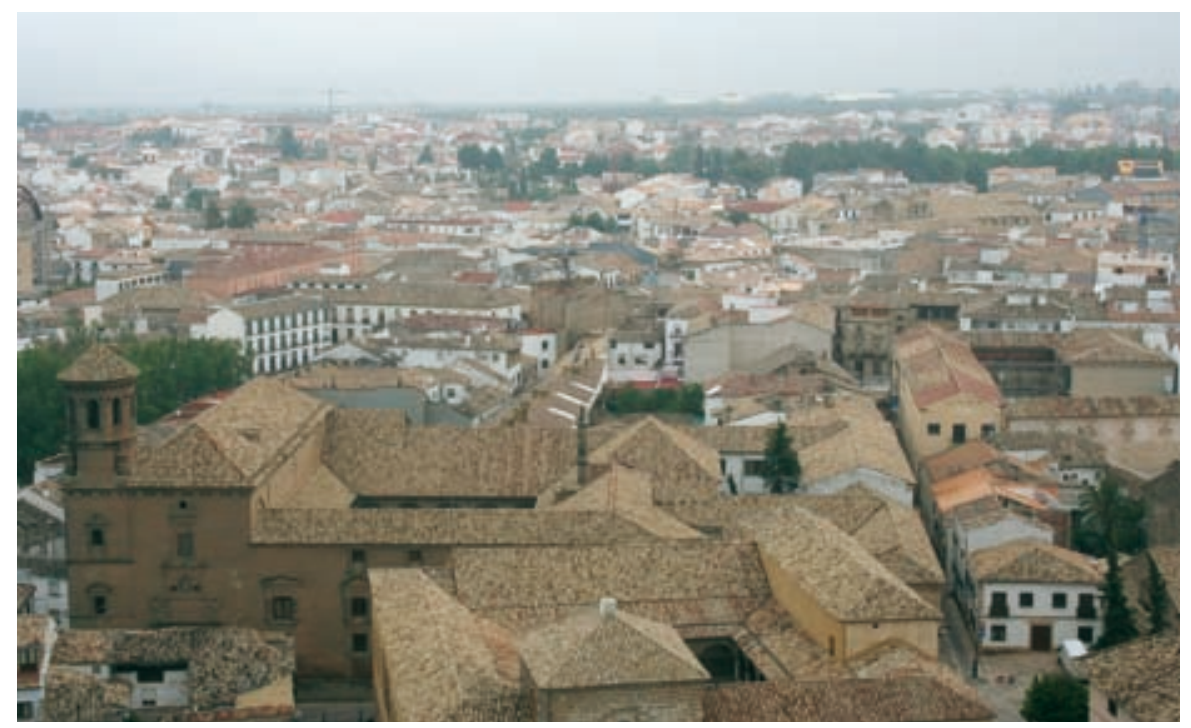

Centro histórico de Baeza. Foto: Antonio Ortega Ruiz

\begin{abstract}
El Seminario Permanente de Patrimonio Histórico es un proyecto de la Universidad Internacional de Andalucía que tiene como objetivo crear un foro de debate, investigación e intercambio de experiencias en el campo del patrimonio histórico. El Seminario se ubica en la sede Antonio Machado de Baeza tanto por el entorno patrimonial en que se encuentra como por su larga trayectoria de contribución al estudio y la formación sobre la conservación, uso y gestión del patrimonio a través de las actividades generadas por el Centro Andaluz de Estudios para el Desarrollo Rural.
\end{abstract}

La iniciativa de la UNIA, que hizo su presentación pública el día 29 de enero con una conferencia de José Javier Rivera Blanco, catedrático de Historia de la Arquitectura y de la Restauración de la ción entre ocio, cultura y turismo, tanto el concepto como el uso y la intervención sobre el patrimonio han venido adquiriendo nuevos perfiles. El concepto de patrimonio se ha ampliado al tiempo que ha ido tomando naturaleza como recurso, interrelacionándose con otros conceptos como territorio, medio natural, desarrollo y turismo. Paralelamente, tanto la iniciativa privada como las administraciones públicas han ido mostrando un creciente interés por el patrimonio, sobre todo en su dimensión económica. Todo ello está generando cambios tan profundos que abren disyuntivas para conciliar, en el ámbito del patrimonio, desarrollo y sostenibilidad, oportunidades y peligros, las necesidades de socialización del uso del patrimonio y las tendencias a su mercantilización en función exclusiva de las fuerzas del mercado y los intereses privados o políticos más inmediatos. La recuperación, conservación, intervención, uso y gestión del patrimonio desde presupuestos de sostenibilidad y autenticidad, el papel de la sociedad civil, de los poderes públicos y de la iniciativa privada, la importancia del patrimonio para el desarrollo territorial, y especialmente el rural, o la naturaleza del turismo cultural, se han convertido en importantes retos para la sociedad actual.

Esos son los debates que abordará el Seminario Permanente de Patrimonio Histórico de la UNIA desde una visión amplia, no exclusivamente académica, que aterrice en el territorio y contando con todas la voces implicadas en la problemática del patrimonio. Sus actividades se inician con las jornadas tituladas Patrimonio histórico: nuevos retos, a celebrar en Baeza entre los días 21 y 23 de mayo de 2009, y el curso de verano Patrimonio Histórico: otras miradas, que se acercará a la realidad patrimonial desde visiones alternativas como la fotografía, la literatura, el cine, las artes plásticas, la música o la mirada subjetiva del viajero interesado.

Desde que a finales del pasado siglo XX los cambios económicos, sociales y culturales propiciaron un estrechamiento de la rela-
Antonio Ortega Ruiz

Coordinador del Seminario Permanente de

Patrimonio Histórico de la UNIA 